\title{
Screening of liquid media and fermentation of an endophytic Beauveria bassiana strain in a bioreactor
}

\author{
Rieke Lohse, Desiree Jakobs-Schönwandt and Anant V Patel ${ }^{*}$
}

\begin{abstract}
A novel approach for biological control of insect pests could be the use of the endophytic entomopathogenic Beauveria bassiana isolate ATP-02. For the utilization of the endophyte as a commercial biocontrol agent, the fungus has to be mass-produced. B. bassiana was raised in shake flask cultures to produce high concentrations of total spores (TS), which include blastospores (BS) and submerged conidiospores (SCS). The highest concentration of $1.33 \times 10^{9} \mathrm{TS} / \mathrm{mL}$ and the highest yield of $5.32 \times 10^{10} \mathrm{TS} / \mathrm{g}$ sucrose was obtained in the TKI broth with $5 \%$ sugar beet molasses which consists of $50 \%$ sucrose as a carbon source. In spite of the lower sugar concentration (2.5\%) the amount of TS could be increased up to 11-times in contrast to the cultivation with 5\% sucrose. The scale-up to a $2 \mathrm{~L}$ stirred tank reactor was carried out at $25^{\circ} \mathrm{C}, 200-600 \mathrm{rpm}$ and $1 \mathrm{vvm}$ at $\mathrm{pH} 5.5$. A TS yield of $5.2 \times 10^{10} \mathrm{TS} / \mathrm{g}$ sucrose corresponding to a SCS yield of $0.2 \times 10^{10} \mathrm{SCS} / \mathrm{g}$ sucrose was obtained after $216 \mathrm{~h}$. With regards to the culture medium the cost of $10^{12}$ TS amounts to $0.24 €$. Plutella xylostella larvae, which were fed with oilseed rape leaves treated with spores from fermentation resulted in $77 \pm 5 \%$ mortality. Moreover, spores from submerged cultivation were able to colonize oilseed rape leaves via leaf application. This is the first report of fermentation of an endophytic B. bassiana strain in a low-cost culture medium to very high yields of TS.
\end{abstract}

Keywords: Submerged culture; Fermentation; Beauveria bassiana; Endophyte; Blastospores; Submerged conidiospores; Biological control

\section{Introduction}

In the past decades, many microorganisms have been isolated and investigated for use as a biocontrol agent. Now, many promising strains are available for release into the environment and especially with the renewed interest in biocontrol await further exploitation for large-scale application in agriculture (Glare et al. 2012). The first step for commercialization of a biocontrol agent like Beauveria bassiana is the mass-production by fermentation (Burges 1998; Ravensberg 2011). B. bassiana strains that were applied to the insect and act on the outer surface of the plant show efficacy against a wide range of insect pests and have the potential of becoming a costeffective biocontrol agent (Khachatourians 1986). However, the approved products of B. bassiana contain aerial conidia (AC), which are produced by either a solid-state

\footnotetext{
* Correspondence: anant.patel@fh-bielefeld.de

Department of Engineering and Mathematics, University of Applied Sciences, Wilhelm-Bertelsmann-Str. 10, Bielefeld 33602, Germany
}

or a diphasic fermentation. These processes are in classical biotechnology considered to be labour-intensive and unsuitable for conventional production of fungal biomass (Feng et al. 1994; Patel et al. 2011; Ravensberg 2011; Rombach et al. 1988). In contrast to these propagules, blastospores (BS) and submerged conidiospores (SCS) would be produced in submerged cultivations in a shorter time with higher yields and state-of-the-art process control. Furthermore, it was shown that BS and SCS of a $B$. bassiana isolate are as virulent to grasshoppers as the AC (Hegedus et al. 1992). Until today, no products with BS or SCS of B. bassiana are available. A few reports on growth requirements and shake flask culture of $B$. bassiana strains show the best growth and germination in complex media (Bidochka et al. 1987; Chong-Rodríguez et al. 2011; Hegedus et al. 1990; Humphreys et al. 1990; Pham et al. 2009; Rombach 1989; Safavi et al. 2007; Samsináková 1966; Thomas et al. 1987; Vega et al. 2003). However, only a few publications deal with the production of mycelium 
(Núñez-Ramírez et al. 2012) and the production of BS in complex (Humphreys et al. 1989, 1990) and mineral media (Lane et al. 1991) by submerged fermentation, respectively. Endophytic B. bassiana strains can exist asymptomatically in a variety of plants like banana (Akello et al. 2008), opium poppies (Quesada-Moraga et al. 2006), maize (Bing and Lewis 1992) and sorghum (Tefera and Vidal 2009). The recently isolated endophytic B. bassiana strain ATP-02 showed great potential for a novel plant control measure in a variety of crops (Tefera and Vidal 2009). However, it remained unknown if this strain can be mass-produced to high yields and if the spores from a submerged fermentation are able to colonize plants. That is why the objective of the present work was to produce spores of endophytic B. bassiana ATP-02 in a costeffective culture medium on lab-scale and to scale-up the process to a $2 \mathrm{~L}$ stirred-tank reactor. Finally the virulence of the produced spores was checked in a bioassay with Plutella xylostella and their potential to colonize oilseed rape leaves via a leaf application was investigated.

\section{Materials and methods}

All materials used were purchased from Merck KGaA (Darmstadt, Germany), Carl Roth GmbH (Karlsruhe, Germany) or AppliChem GmbH (Darmstadt, Germany), if not mentioned otherwise. Sugar beet molasses with a dry matter content of $80 \%$ consisting of $50 \%$ sucrose was purchased from Suedzucker AG (Mannheim, Germany). All concentrations are given as (w/w).

\section{Strain}

B. bassiana isolate ATP-02, DSM 24665, was provided by Prof. Stefan Vidal, Georg-August-University, Department of Crop Sciences/Agricultural Entomology, Goettingen, Germany. The strain was raised at $25^{\circ} \mathrm{C}$ on SDA agar containing $1 \%$ casein peptone, $2 \%$ glucose and $1.5 \%$ agar-agar at $\mathrm{pH}$ 5.5. Temperature optimum was found at $25^{\circ} \mathrm{C}$ and $\mathrm{pH}$ optimum at 5.5 (data not shown).

\section{Cultivation in shake flask culture}

Different liquid media were used to cultivate $B$. bassiana: TKI medium with 5\% carbon source (Thomas et al. 1987), Czapek-Dox medium (Kučera 1971), YPG medium and PG medium (Bidochka et al. 1987), Vogel's medium (Vogel 1956), SD medium (Odds 1991), CGM medium containing $1 \%$ glucose, $1 \%$ corn steep liquor, $0.5 \% \mathrm{NaCl}, 0.1 \%$ $\mathrm{NaNO}_{3}, 1 \% \mathrm{CaCO}_{3}$ (Samsináková 1966), PWG medium containing $1 \%$ glucose, $8.75 \%$ whey powder, $0.25 \%$ peptone (Kassa et al. 2008), YG medium containing 1\% glucose, $1 \%$ yeast extract (Leckie et al. 2008), YSM medium containing $2 \%$ sucrose, $0.5 \%$ yeast extract, $0.15 \% \mathrm{KH}_{2} \mathrm{PO}_{4}$, $0.05 \% \mathrm{MgSO}_{4} \cdot 7 \mathrm{H}_{2} \mathrm{O}, 0.001 \% \mathrm{CaCl}_{2}, 0.000003 \% \mathrm{H}_{3} \mathrm{BO}_{3}$, $0.000004 \% \mathrm{MnSO}_{4} \cdot 4 \mathrm{H}_{2} \mathrm{O}, 0.0000025 \% \mathrm{Na}_{2} \mathrm{MoO}_{4} \cdot 2 \mathrm{H}_{2} \mathrm{O}$, $0.000008 \% \mathrm{CuSO}_{4} \cdot 5 \mathrm{H}_{2} \mathrm{O}, 0.00004 \% \mathrm{ZnSO}_{4} \cdot 7 \mathrm{H}_{2} \mathrm{O}, 0.00005 \%$
$\mathrm{FeCl}_{3} \cdot 6 \mathrm{H}_{2} \mathrm{O}, 0.00004 \% \mathrm{CoCl}_{2} \cdot 6 \mathrm{H}_{2} \mathrm{O}$ (Rombach 1988,1989 ) and YS medium containing 2.5\% sucrose, $2.5 \%$ yeast extract (Rombach 1989). In each case $50 \mathrm{~mL}$ medium was

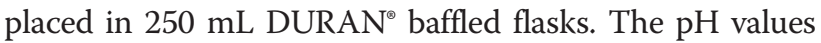
of the media were adjusted to 5.5 with $0.5 \mathrm{M} \mathrm{NaOH}$. As a starter inoculum AC from SDA agar (see above) were used. The AC were isolated by flooding the plates with $2 \times 5 \mathrm{~mL}$ of sterile $0.1 \%$ Tween 80 and gently raking the plates with a sterile bristle brush. The shake flask cultures were inoculated with the spore suspension to give an initial spore density of $5.0 \times 10^{4} \mathrm{AC} / \mathrm{mL}$. The flasks were incubated at $25^{\circ} \mathrm{C}$ on a rotary shaker at a speed of $150 \mathrm{rpm}$ for 8-10 days. Every day, $1 \mathrm{~mL}$ samples were taken to check developmental stage and the concentration of the spores with a Thoma counting cell chamber under $400 \times$ magnification (photomicroscope, Carl Zeiss AG, Oberkochen, Germany).

\section{Fermentation}

Batch fermentation was carried out in a 2 L BIOSTAT $^{\oplus}$ Bplus stirred tank reactor (Sartorius Stedim System $\mathrm{GmbH}$, Guxhagen, Germany) with a working volume of

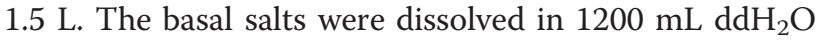
and were autoclaved in the bioreactor. Also, a few drops of the anti-foam agent Pluronic ${ }^{\oplus}$ PE 8100 (BASF SE, Ludwigshafen, Germany) were added before fermentation started. Likewise, $300 \mathrm{~mL}$ of a carbon source stock solution (75 g carbon source) were autoclaved separately and were inoculated with $7.5 \times 10^{8}$ aerial conidia $\left(5.0 \times 10^{4}\right.$ spores $/ \mathrm{mL}$ ). To start the fermentation, the inoculum suspension was added to the bioreactor. Temperature was maintained at $25^{\circ} \mathrm{C}$ and fermentation time was between $8-10$ days.

\section{Analysis}

The metabolic respiratory quotient (RQ) is an on-line parameter for the formation of biomass was calculated from the ratio of the generated carbon dioxide and the consumed oxygen, which were measured with an $\mathrm{O}_{2}$ and $\mathrm{CO}_{2}$ sensor (BlueSens $\mathrm{GmbH}$, Herten, Germany) in the exhaust air. For the determination of fungal dry biomass $15 \mathrm{~mL}$ samples were centrifuged for $10 \mathrm{~min}$ at 20,000 $\mathrm{g}$, washed two times with $\mathrm{ddH}_{2} \mathrm{O}$ and centrifuged again. The pellets were suspended in $5-7 \mathrm{~mL}$ of $\mathrm{ddH}_{2} \mathrm{O}$. The cell suspensions were dried at $115^{\circ} \mathrm{C}$ to constant weight using a moisture analyzer (Sartorius AG, Goettingen, Germany). Each time, determination of fungal dry biomass was carried out in two replicates.

The colony forming units (CFU) of BS and SCS were determined by spreading $100 \mu \mathrm{L}$ of diluted samples on SDA plates (Odds 1991) and incubating at $25^{\circ} \mathrm{C}$ for $4-6$ days. To ensure that a sample will yield CFU in a range between 50 and 150 colonies requires several 10-fold dilutions of the sample with $0.9 \% \mathrm{NaCl}$. The CFU were 
determined on duplicate samples. The $\mathrm{CFU} / \mathrm{ml}$ was calculated as follows:

$$
\frac{C F U}{m L}=\frac{C F U}{\text { plate }} \cdot \frac{\text { dilution factor }}{0.1 m L}
$$

\section{Insect virulence assay}

Bioassays were conducted with 30 second instar larvae of Plutella xylostella L. (Yponomeutidae: Lepidoptera), which were provided by Prof. Stefan Vidal, Georg-AugustUniversity, Department of Crop Sciences/ Agricultural Entomology, Goettingen, Germany. The culture broth of the fermentation was centrifuged for $5 \mathrm{~min}$ at $20,000 \mathrm{~g}$, washed two times with $\mathrm{ddH}_{2} \mathrm{O}$ and centrifuged again. The washed spore mix, consisting of $95 \%$ BS and 5\% SCS, as well as pure AC from a two-weeks-old SDA culture were suspended in $0.1 \%$ Triton-X114 to obtain a final concentration of $10^{6}$ viable spores $/ \mathrm{mL}$. Aliquots of $1 \mathrm{~mL}$ of the suspensions were brushed on the adaxial side of secondary oilseed rape leaves with an area of $80 \pm 10 \mathrm{~cm}^{2}$. The control leaves were treated with $0.1 \%$ Triton-X114 only. High $500 \mathrm{~mL}$ beakers were filled with $100 \mathrm{~mL}$ water agar $(1.0 \%$ agar-agar). In each case three stalks of the treated leaves were drilled into the solid water agar. The upper surface of the water agar was covered with sterile filter paper to prevent the larvae from getting stuck. Afterwards, ten larvae were transferred into each of the beakers with and without spores, respectively. The beakers were closed with silk gauze and incubated at room temperature.

After 14 days, the dead larvae were surface sterilized with $70 \%$ ethanol for $2 \mathrm{~min}$, 5\% sodium hypochlorite for $3 \mathrm{~min}$ and $70 \%$ ethanol for $2 \mathrm{~min}$, rinsed twice in sterile distilled water, and then placed on sterile tissue paper in a laminar airflow cabinet. The larvae were placed on a modified $B$. bassiana selective medium, consisting of $1 \%$ casein peptone, 4\% glucose, $0.1375 \%$ Syllit ${ }^{\circ}$ (Spiess-Urania Chemicals $\mathrm{GmbH}$, Hamburg, Germany), 0.0005\% chlortetracycline, $0.0005 \%$ crystal violet and 1.5\% agar-agar (Chase et al. 1986; Rangel et al. 2010), and were incubated at $25^{\circ} \mathrm{C}$ for 1 week. To evaluate the efficacy of the surface sterilization method the water used to rinse the tissues after surface sterilization was plated on selective medium and was incubated, too.

After re-isolation, the DNA of the mycelium was extracted. In each case $50 \mathrm{mg}$ mycelium were cooled on ice, and $1 \mathrm{~mL}$ CTAB buffer (0.02 M Na-EDTA, $126 \mathrm{mM}$ sorbitol, $36.8 \mathrm{mM}$-laurylsarcosine, $22 \mathrm{mM} \mathrm{CTAB}, 90 \mathrm{mM}$ polyvinylpyrrolidone, $10 \mathrm{mM}$ Tris, $0.8 \mathrm{M} \mathrm{NaCl}$ at $\mathrm{pH} 8.0$ ), $2 \mu \mathrm{L} \beta$-mercaptoethanol and $1 \mu \mathrm{L}$ proteinase $\mathrm{K}(0.1 \mathrm{~g} / \mathrm{L})$ were added. The samples were incubated at $42^{\circ} \mathrm{C}$ for $10 \mathrm{~min}$, at $65^{\circ} \mathrm{C}$ for $10 \mathrm{~min}$, and then $800 \mu \mathrm{L}$ chloroform: isoamylalcohol 24:1 were added, mixed, stored on ice for $10 \mathrm{~min}$ and centrifuged at $8,000 \mathrm{rpm}$ for $10 \mathrm{~min}$. The supernatants were carefully taken, mixed with $100 \mu \mathrm{L} 5 \mathrm{M}$
$\mathrm{NaCl}$ and $200 \mu \mathrm{L} 30 \%$ PEG, stored for $10 \mathrm{~min}$ at room temperature and centrifuged at $14,000 \mathrm{rpm}$ for $15 \mathrm{~min}$. The pellets were washed twice with $600 \mu \mathrm{L} \mathrm{75 \%} \mathrm{ethanol}$ and dried in a thermoblock at $65^{\circ} \mathrm{C}$. Afterwards, the DNA pellet was dissolved in $100 \mu \mathrm{L}$ TE buffer $(10 \mathrm{mM}$ Tris at $\mathrm{pH}$ 8.0) and stored at $-20^{\circ} \mathrm{C}$. All samples were assessed by PCR using specific primers namely RD1-F (5' - TGGGT ATAGGCCGCAGCAC-3') and RD1-R (5' - CTCTAAGG GTGACAGGGATAG-3') which amplify a 208-bp region of the ITS1-5.8S-ITS2 region of B. bassiana. The primer sequences were compared with the NCBI nucleotide database using BLAST and were predicted to be $100 \%$ homologous to B. bassiana isolate DAOM210087 as well as ATP-02. All amplifications were performed in a TProfessional (Biometra GmbH, Goettingen, Germany) thermocycler. PCR reactions consisted of a reaction mix (final volume $10 \mu \mathrm{L}$ ) of $1 \mu \mathrm{l} 10 \mathrm{x}$ reaction buffer, $2.5 \mathrm{mM}$ $\mathrm{MgCl}_{2}, 100 \mu \mathrm{M}$ dNTPs, $0.3 \mu \mathrm{M}$ RD1-F primer, $0.3 \mu \mathrm{M}$ RD1-R primer, $0.3 \mathrm{U}$ Taq polymerase (5 Prime $\mathrm{GmbH}$, Hilden, Germany) and $1 \mu \mathrm{l}$ template DNA (30 ng). The cycling program included an initial denaturation step of 5 min at $95^{\circ} \mathrm{C}$, followed by 35 cycles of 1 min denaturation at $95^{\circ} \mathrm{C}, 1 \mathrm{~min}$ annealing at $59^{\circ} \mathrm{C}$, and $1 \mathrm{~min}$ extension at $72^{\circ} \mathrm{C}$. Amplification products were mixed with GelRed ${ }^{\mathrm{mx}}$ (Biotium Inc., Hayward, Canada), separated by electrophoresis in $1.5 \%$ agarose gels in $1 \times$ TBE buffer $(89 \mathrm{mM}$ Tris, $89 \mathrm{mM}$ boric acid, $2 \mathrm{mM}$ EDTA at $\mathrm{pH}$ 8.0) for $60 \mathrm{~min}$ at $100 \mathrm{~V}$ and visualized under UV radiation.

All tests were run for 14 days and each test was repeated thrice. The mortality data were analyzed statistically using one-way ANOVA test.

\section{Penetration assay}

Native oilseed rape (Brassica napus L.) cultivar "PULSAR" was obtained from the Deutsche Saatveredelung AG (Lippstadt, Germany). The seeds were planted singly in pots containing sterile soil/sand substrate $(1: 3(\mathrm{v} / \mathrm{v}))$ (Fruhstorfer Erde Type T25, HAWITA Group GmbH, Vechta, Germany) and were cultivated under greenhouse conditions, The plants were maintained at $18-22^{\circ} \mathrm{C}$, 40-60\% RH for 16 weeks and with a 12-h photoperiod (SON-T Agro $400 \mathrm{~W}$, Philips, Amsterdam, Netherlands).

Formulation components consisting of $0.1 \%$ Triton $\mathrm{X}-114$ as a wetter, $0.1 \%$ gelatine 280 Bloom (Gelita AG, Goeppingen, Germany) as a humectant, $1 \%$ sugar beet molasses as nutrient and $1 \%$ titanium dioxide as a UV protection agent were autoclaved for $20 \mathrm{~min}$ at $121^{\circ} \mathrm{C}$. The spore suspension from a submerged fermentation was centrifuged for $5 \mathrm{~min}$ at $20,000 \mathrm{~g}$, washed twice with $\mathrm{ddH}_{2} \mathrm{O}$ and centrifuged again. Afterwards the spores were suspended in $0.9 \% \mathrm{NaCl}$ and added to the formulation components up to a final concentration of $10^{6}$ spores $/ \mathrm{mL}$. The control formulation was free of fungal biomass. Then, the formulations were brushed onto an 
area of approximately $3 \mathrm{~cm}$ of the tips of $9^{\text {th }}$ secondary leaves oilseed rape plants. To increase the relative humidity up to $95 \%$, the treated leaves were wrapped with plastic bags for the first $48 \mathrm{~h}$. After 7 days the leaf tips were cut off and the untreated base of the leaves were harvested for the detection of endophytic colonization with $B$. bassiana by microscopy and PCR.

For microscopy, cross-sections of the leaf mid rip were stained with $0.5 \%$ rose bengal dissolved in $5 \%$ aqueous ethanol for $15 \mathrm{sec}$ and were washed with $\mathrm{ddH}_{2} \mathrm{O}$ (Saha et al. 1988). Growth of B. bassiana in the plant tissue was detected at 200-fold magnification with a light microscope. Afterwards, the leaves were surface sterilized as mentioned above and then placed on sterile tissue paper in a laminar airflow cabinet. In a preliminary test it was shown that this surface sterilization method kills all spores which were applied onto oilseed rape leaves.

For DNA extraction which was described above, approximately $400 \mathrm{mg}$ plant tissue from the surface sterilized leaves and stems was taken. The plant tissue was crushed in a MM400 ball mill using a sterile $5 \mathrm{~mm}$ steel ball (Retsch GmbH, Haan, Germany) for $5 \mathrm{~min}$ at $30 \mathrm{~Hz}$. To isolate B. bassiana DNA from a SDA culture, $50 \mathrm{mg}$ fungal biomass were directly used for DNA extraction. All tissue samples of both treated and untreated oilseed rape plants were assessed by PCR.

\section{Results}

\section{Screening of media in shake flask culture}

The entomopathogenic and endophytic fungus B. bassiana isolate ATP-02 was cultivated in shake flasks. The different liquid media described above were used to study the effect of various nutrients, basal salts and other complex components on submerged spore formation. In Figure 1 the concentrations and yields of total spores (TS) with regard to the different culture media are illustrated. The most promising culture medium with regard to a maximum growth and optimum sporulation was the TKI medium with $5 \%$ sucrose as a carbon source: After a cultivation time of $168 \mathrm{~h} \mathrm{~B}$. bassiana produced TS in a concentration of $1.10 \pm 0.01 \times 10^{8} \mathrm{TS} / \mathrm{mL}$ consisting of $100 \%$ BS. In this TKI medium a yield of $2.20 \pm 0.02 \times 10^{9}$ TS/g sucrose was obtained. Due to the lower substrate concentration of $2 \%$ sucrose and the also high concentration of $1.09 \pm 0.08 \times 10^{8} \mathrm{TS} / \mathrm{mL}$ in the YSM medium a yield of $5.43 \pm$ $0.38 \times 10^{9} \mathrm{TS} / \mathrm{g}$ sucrose was obtained. However, in contrast to the TKI medium, the YSM medium contains $0.5 \%$ yeast extract as a complex component. In all cases, the achieved concentration of SCS was lower than $11 \%$ of the TS. The highest, but still low SCS concentration of $0.29 \pm$ $0.04 \times 10^{6} \mathrm{SCS} / \mathrm{mL}$ was obtained in the YG medium.

\section{Influence of different carbon sources on spore formation of B. bassiana}

B. bassiana ATP-02 was cultured in TKI medium which was supplemented with $5 \%$ of different pure carbon sources according to Thomas et al. (1987). Furthermore, TKI medium was supplemented with 5\% sugar beet molasses as a complex carbon source which consisted of $50 \%$ sucrose according to manufacturer specification (Suedzucker AG, Mannheim, Germany). In Figure 2 a and $\mathrm{b}$ the concentrations of TS and SCS with regard to

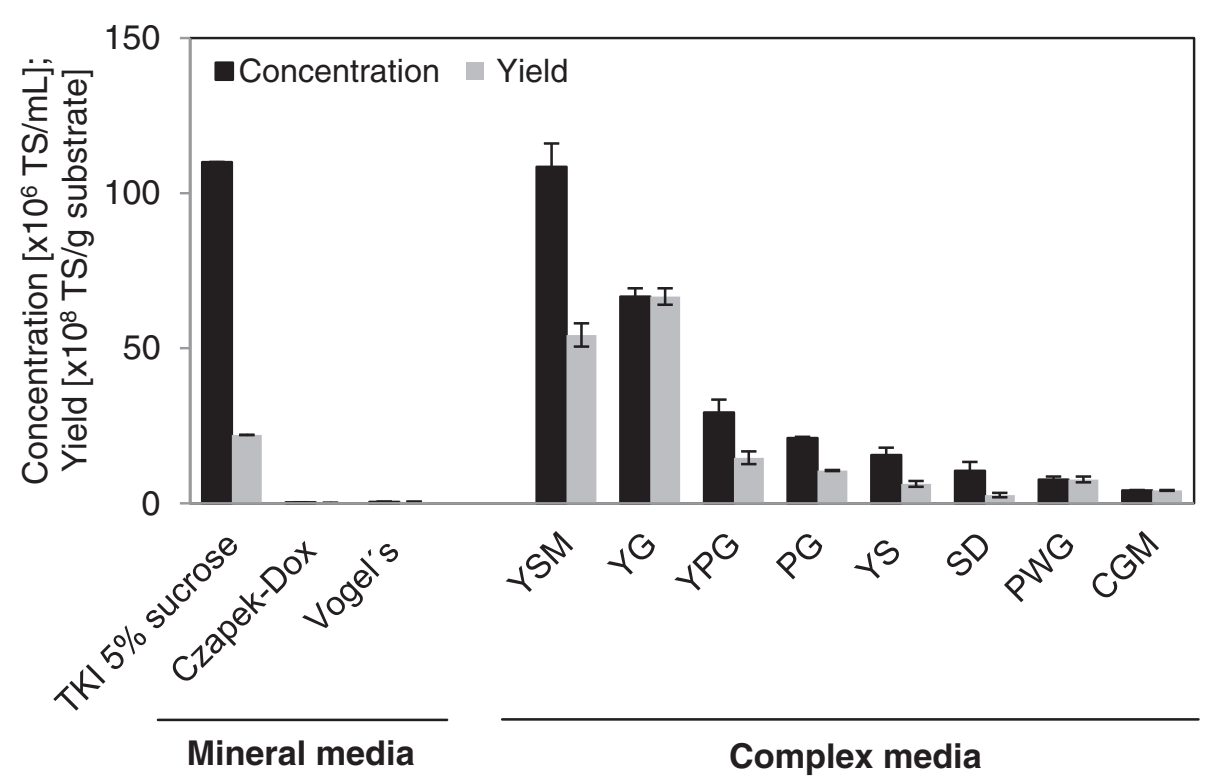

Figure 1 Influence of different culture media on spore formation. B. bassiana was cultivated in $250 \mathrm{~mL}$ shake flasks $(n=2)$. Mean $( \pm$ SD) concentrations and mean $( \pm$ SD) yields of TS $168 \mathrm{~h}$ after inoculation. 


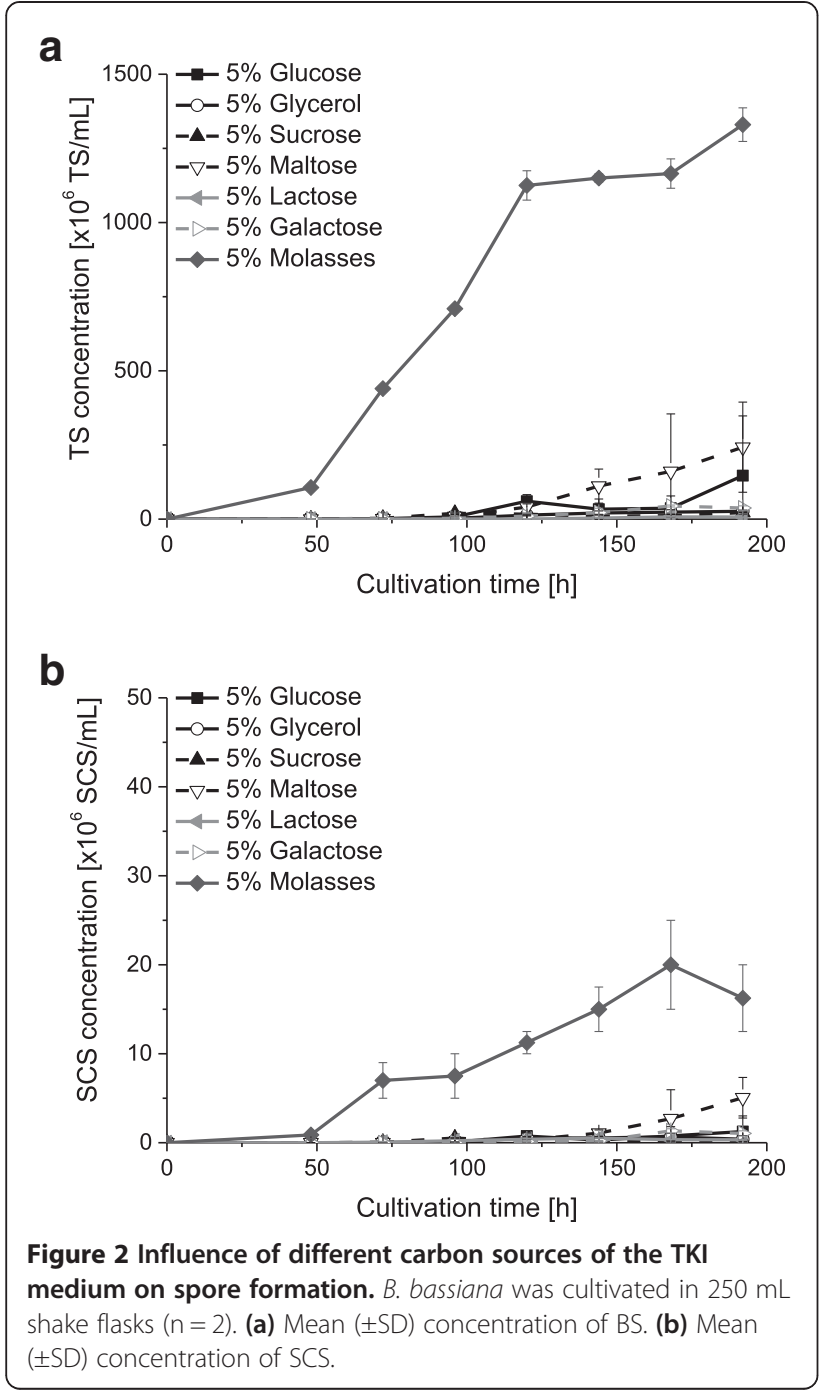

the different carbon sources are illustrated. The highest concentration of $1.17 \pm 0.05 \times 10^{9} \mathrm{TS} / \mathrm{mL}$ corresponding to the highest yield of $4.68 \pm 0.20 \times 10^{10} \mathrm{TS} / \mathrm{g}$ sucrose was obtained in the TKI medium with 5\% sugar beet molasses. Furthermore, in this medium $B$. bassiana also produced the highest concentration of $2.00 \pm 0.50 \times 10^{7}$ SCS $/ \mathrm{mL}$ corresponding to a SCS yield of $8.00 \pm 2.00 \times 10^{8}$ SCS/mL $168 \mathrm{~h}$ after inoculation. However, the biomass consisted of more than $98 \%$ BS. In spite of the lower sugar concentration of the molasses $(2.5 \%)$ the concentration of TS could be increased up to 11-times in contrast to the cultivation with $5 \%$ sucrose. Due to the lower sugar concentration the yield of TS could be even increased up to 21-times.

Interestingly, when TKI basal salts were omitted from the $5 \%$ molasses medium, TS concentration decreased by $96 \%$ compared to cultivation in the original TKI medium (data not shown).

\section{Fermentation of B. bassiana ATP-02}

B. bassiana ATP-02 was raised in a $2 \mathrm{~L}$ stirred tank reactor to produce high concentrations of TS. Based on the cultivations in shake flasks $B$. bassiana ATP-02 was cultivated in the mineral TKI medium with $5 \%$ sugar beet molasses and were inoculated with $5 \times 10^{4} \mathrm{AC} / \mathrm{mL}$. The fermentation conditions and growth parameters are given in Table 1. During $48 \mathrm{~h}$ fermentation time, $12.6 \mathrm{~g} / \mathrm{L}$ dry biomass was produced. Maximal specific growth rate $\mu_{\max }$ was $0.14 \mathrm{~h}^{-1}$. Average doubling time was $14.7 \mathrm{~h}$. The minimal doubling time of $4.9 \mathrm{~h}$ was reached between 48 and $72 \mathrm{~h}$ after inoculation. The results of the fermentation could be verified in 7 sequentially performed runs, which are shown in Table 2.

The Figure $3 \mathrm{a}$ and $\mathrm{b}$ show the details of the fermentation no. 1 . The fermentation process can be subdivided in two phases: a phase of mycelium formation and a following phase of spore formation.

At the beginning of the fermentation the amount of dry biomass increased because the fungus produced mycelium. After $62 \mathrm{~h}$ a sudden decrease of the RQ to 0.6 followed by a sharp decrease of $\mathrm{pH}$ to 4.7 , a short recuperation of $\mathrm{RQ}$ and a decrease of $\mathrm{pO}_{2}$ to $4 \%$ was observed. A sample taken shortly thereafter at $72 \mathrm{~h}$ still yielded $21 \mathrm{~g}$ biomass/L and the broth was still visibly viscous. Then, biomass dry weight decreased which was accompanied by a visible reduction of mycelium. Preliminary HPLC data indicated a formation of oxalate (data not shown). At this time the concentration of TS started to increase up to $1.29 \pm 0.04 \times 10^{9} \mathrm{TS} / \mathrm{mL}$ corresponding to a yield of $5.16 \pm 0.16 \times 10^{10} \mathrm{TS} / \mathrm{g}$ sucrose at the end of the fermentation. However, the biomass consisted of more than 95\% BS. $96 \mathrm{~h}$ after inoculation the viability of TS started to decrease. The maximum concentration of $0.84 \times 10^{9}$ viable spores $/ \mathrm{mL}$ corresponding to a yield of $3.36 \times 10^{10}$ viable spores/g sucrose was obtained $168 \mathrm{~h}$

Table 1 Cultivation of B. bassiana ATP-02 in a 2 L stirred tank reactor: fermentation conditions and growth parameters

\begin{tabular}{ll}
\hline Fermentation conditions & \\
\hline Inoculum [aerial conidia/mL] & $5 \times 10^{4}$ \\
Start pH $[-]$ & 5.5 \\
Stirrer speed $[\mathrm{rpm}]$ & 600 \\
Aeration rate $[\mathrm{vvm}]$ & 1.0 \\
Aeration rate $[\mathrm{L} / \mathrm{min}]$ & 1.5 \\
Temperature $\left[{ }^{\circ} \mathrm{C}\right]$ & 25
\end{tabular}

Growth parameters

Biomass produced (after $48 \mathrm{~h}$ ) [g/L] 12.6

Max. specific growth rate $\mu_{\max }\left[h^{-1}\right] \quad 0.14$

Min. doubling time $[\mathrm{h}] \quad 4.9$

Mean doubling time [h] 
Table 2 Cultivation of B. bassiana ATP-02 in 7 sequentially performed fermentation runs

\begin{tabular}{lll}
\hline No. & $\begin{array}{l}\text { Total spores } \\
{\left[\times 10^{9} \mathrm{TS} / \mathrm{mL}\right]}\end{array}$ & $\begin{array}{l}\text { Submerged conidiospores } \\
{\left[\times 10^{9} \mathrm{SCS} / \mathrm{mL}\right]}\end{array}$ \\
\hline 1 & $1.11 \pm 0.00$ & $0.04 \pm 0.00$ \\
2 & $1.45 \pm 0.01$ & $0.10 \pm 0.01$ \\
3 & $1.12 \pm 0.01$ & $0.06 \pm 0.01$ \\
4 & $2.08 \pm 0.02$ & $0.12 \pm 0.01$ \\
5 & $1.89 \pm 0.01$ & $0.09 \pm 0.02$ \\
6 & $1.39 \pm 0.04$ & $0.08 \pm 0.01$ \\
7 & $1.11 \pm 0.09$ & $0.04 \pm 0.01$ \\
\hline
\end{tabular}

Achieved mean $( \pm$ SD) concentrations of TS and SCS $168 \mathrm{~h}$ after inoculation. Standard deviations were calculated from two technical replicates.

after inoculation. During the further fermentation process the concentration of viable spores decreased to $0.78 \times 10^{9}$ $\mathrm{TS} / \mathrm{mL}$ corresponding to a yield of $3.12 \times 10^{10} \mathrm{TS} / \mathrm{g}$ sucrose at the end of the fermentation. Besides, the biomass dry weight decreased during the spore formation phase from
$21 \mathrm{~g} / \mathrm{L}$ to $12 \mathrm{~g} / \mathrm{L}$. Furthermore, $80 \mathrm{~h}$ after inoculation the $\mathrm{RQ}$ decreased continuously and the $\mathrm{pO}_{2}$ reached a noncritical value of $20 \%$ and a clogging of the $\mathrm{pO}_{2}$ electrode was noted.

\section{Insect virulence assay}

The spore mixture from a submerged fermentation, consisting of 95\% BS and 5\% SCS as well as pure AC harvested from a petri dish were applied in a virulence test against the diamondback moth, $P$. xylostella. After 14 days, in the control without fungal spores $93 \pm 5 \%$ of the larvae developed into viable adult insects. However, $77 \pm 5 \%$ of larvae fed with spore mix-treated leaves as well as $90 \pm 8 \%$ of larvae fed with AC-treated leaves died within a week (Figure 4). The dead larvae were surface sterilized, placed on a $B$. bassiana selective medium and mycelium grew out of all larvae treated with fungal spores and the mycelium was identified as B. bassiana by PCR. The mycelium which grew out of dead larvae not treated with $B$. bassiana was clearly not B. bassiana,

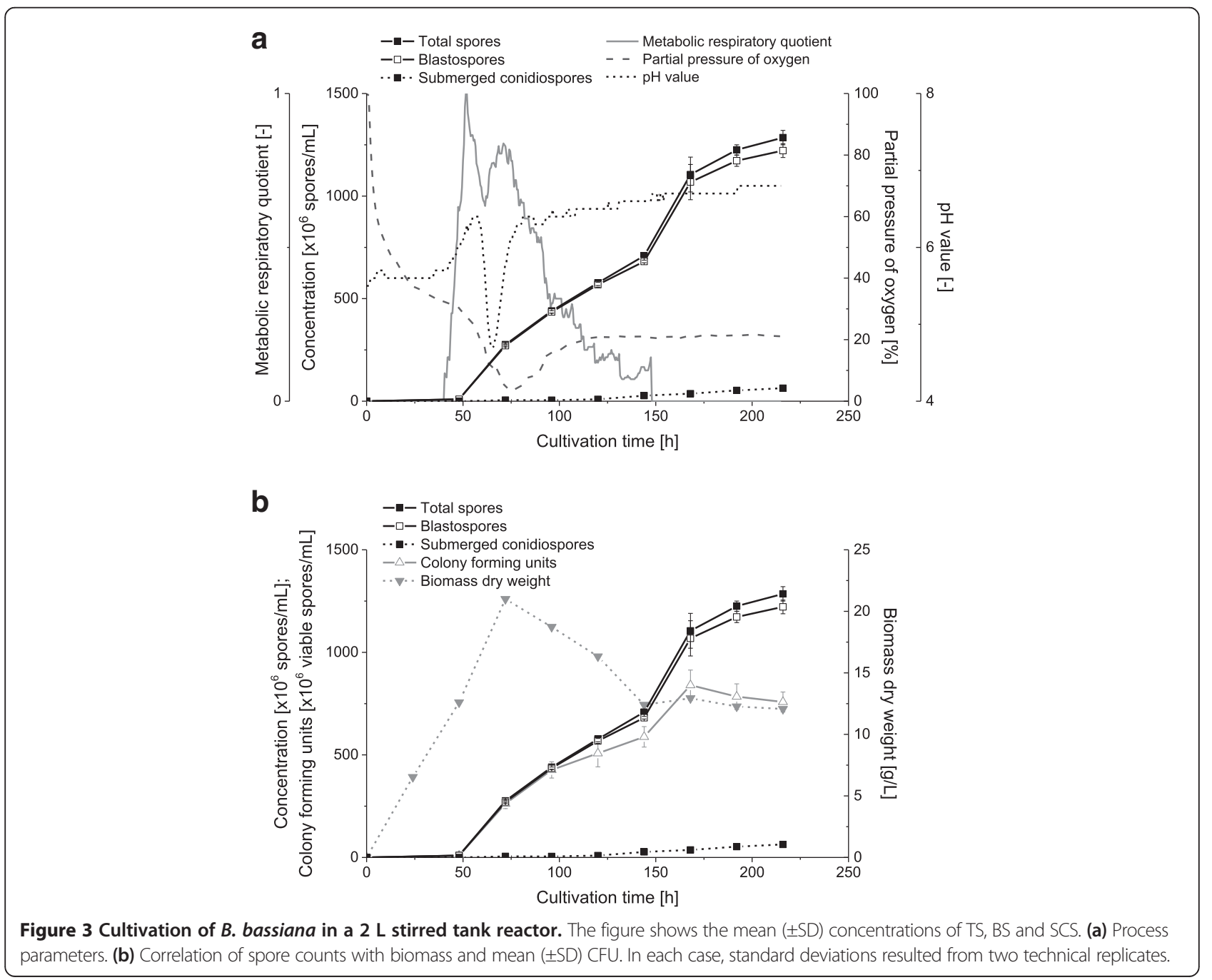




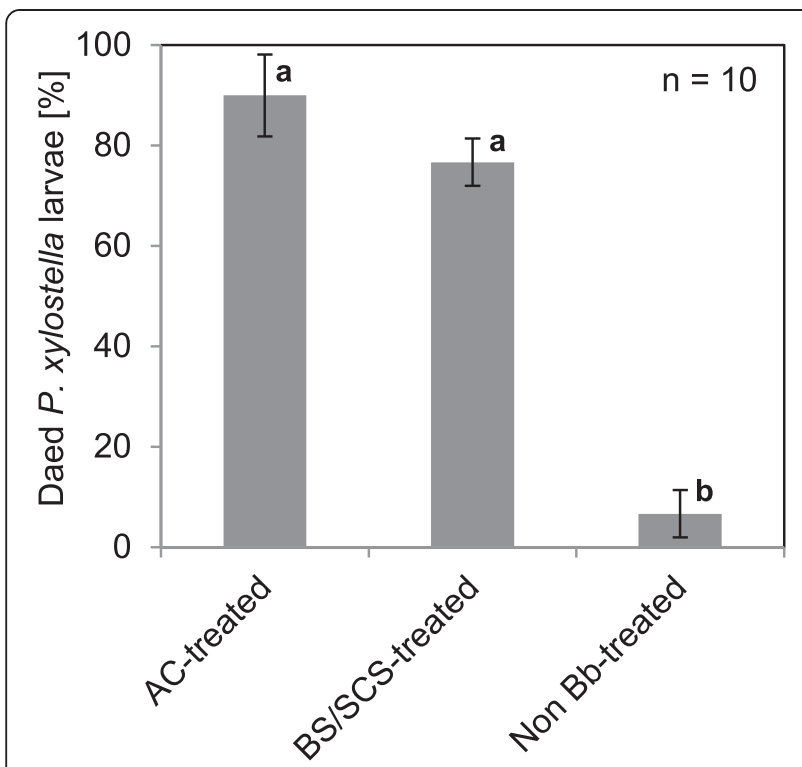

Figure 4 Virulence test with $\boldsymbol{P}$. xylostella larvae. The larvae were fed with AC-treated as well as BS/SCS-treated (95\% BS and 5\% SCS) and non $B$. bassiana (Bb)-treated oilseed rape leaves. Means $( \pm S D)$ followed by different letters are significantly different at $P<0.01$ using one-way ANOVA test. In each case, standard deviations resulted from three replicates with 10 larvae.

so that these larvae did not die by $B$. bassiana induced mycosis. It was observed that the spores from submerged fermentation $\left(\mathrm{P}<0.01 ; \mathrm{F}_{1,4}=220.5\right)$ as well as the pure $\mathrm{AC}\left(\mathrm{P}<0.01 ; \quad \mathrm{F}_{1,4}=156.3\right)$ significantly affected the mortality of larvae. Besides, the number of dead larvae was not significantly affected by the type of spores.

\section{Penetration assay}

The influence of a formulation with $B$. bassiana spores $\left(10^{6} \mathrm{TS} / \mathrm{mL}\right)$ on the penetration of oilseed rape leaves was investigated. The formulation was brushed onto the $9^{\text {th }}$ secondary leaf tips of seven oilseed rape plants and afterwards, endophytic B. bassiana was detected in the tissue of the untreated leaf base by PCR and microscopy. After 7 days, no hyphae growth was observed microscopically in control leaves treated without B. bassiana $(n=2)$. However, hyphae growth was observed in the mid rip cross-sections of $100 \%$ of leaves treated with the formulation. A randomly selected cross-section of these leaf mid rips is illustrated in Figure 5a. To verify that the microscopically detected mycelium was $B$. bassiana, a PCR was performed. B. bassiana was detected in all untreated areas of the leaves treated with the formulation by PCR and subsequent gel electrophoresis. The positive PCR signals of five randomly selected leaves are shown in Figure $5 \mathrm{~b}$ and no PCR amplification was observed in control plants.

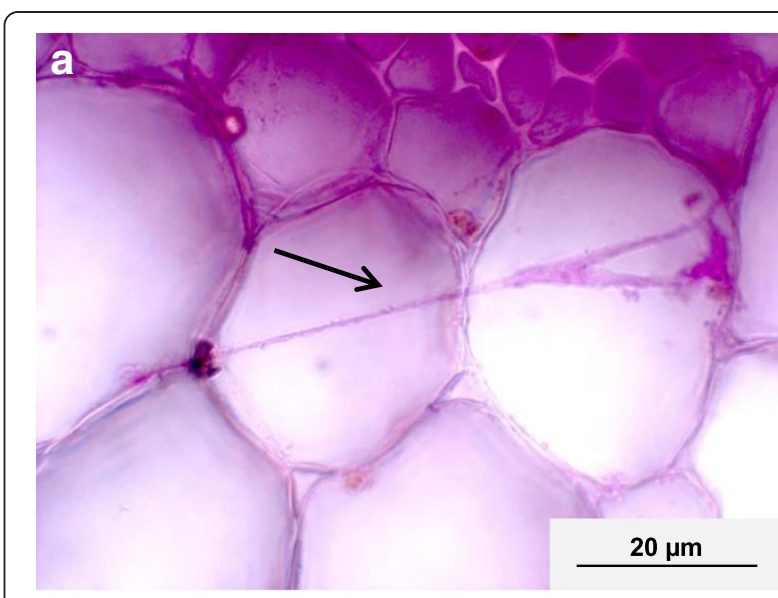

b

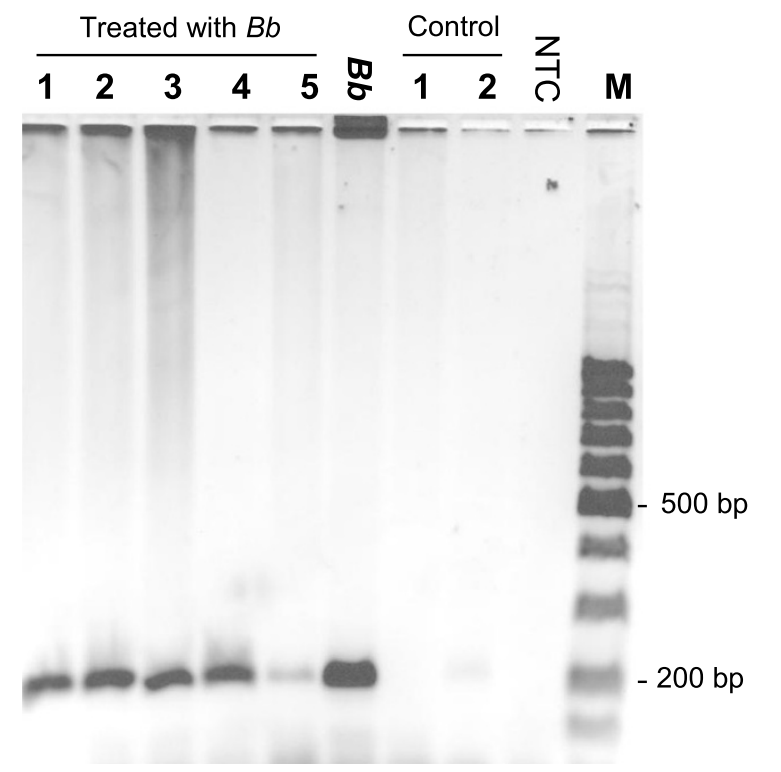

Figure 5 Penetration assay with $B$. bassiana ATP-02. Spray formulations with $(n=7)$ and without $(n=2)$ B. bassiana $(B b)$ were brushed onto the leaf tips. (a) Microscopic detection of $B b$ in a cross-section of a leaf mid rip from a Bb-treated leaf at 200-fold magnification. The arrow marks the hyphae in the leaf tissue. (b) $B b$ was detected in the untreated area of the $B b$-treated leaves by PCR and subsequent gel electrophoresis. Lane 1-5: DNA from $B b$-treated leaves; Lane 6: Bb DNA from pure SDA culture; Lane 7-8: DNA from control-treated leaves; Lane 9: no template control; Lane 10: 100 bp DNA ladder (AppliChem GmbH, Darmstadt, Germany).

\section{Discussion}

This study deals with the fermentation aspects of the endophytic $B$. bassiana ATP-02 which might prepare the way to exploit endophytes as commercial biocontrol agents.

\section{Screening of media in shake flask culture}

In the past, mass-production of $B$. bassiana has focused on $\mathrm{AC}$, but the production through surface cultivation 
or a two-stage process in which the fungus is allowed to develop under submerged conditions and subsequently transferred to a solid media to sporulate requires long cultivation times, large amounts of space and can be labour-intensive (Hall and Papierok 1982). The obvious advantages of a submerged cultivation are that the fungus produces spores in a relatively short time with high yields under controlled sterile conditions as well as a simpler scale-up in contrast to solid-state fermentation (Feng et al. 1994; Hegedus et al. 1992; Patel et al. 2011). It was previously known that B. bassiana strains grow in a variety of liquid mineral and complex media, but that the conidiation of the fungi under submerged conditions may be strain-specific (Kassa et al. 2008) and needs to be investigated for each strain in detail. Furthermore, it was hypothesized that the endophytic B. bassiana strain ATP-02 does not grow in the same way as the established $B$. bassiana strains that are applied in classic biocontrol on the surface of plants or in the soil.

However, results on cultivation in shake flasks showed that $B$. bassiana ATP-02 was able to produce BS in the described culture media. Generally, in a submerged cultivation $B$. bassiana can produce two types of spores, namely BS and SCS. BS are relatively large, thin-walled and single-celled hyphal bodies (Bidochka et al. 1987). SCS, on the other hand, are small, spherical, more uniform in size and show a higher shelf life than BS (Thomas et al. 1987; Hegedus et al. 1992; Holder et al. 2007). They arise from the fungal mycelia or directly from BS in a process known as microcycle conidiation (Smith et al. 1981). Thomas et al. (1987) describe the direct formation of SCS from BS in the mineral TKI medium with $5 \%$ glucose after a cultivation time of $96 \mathrm{~h}$. This phenomenon was not observed in the present work. From the biotechnological point of view the most important properties of the culture medium are high yields of TS and SCS, respectively. Although a higher TS yield was obtained in the YSM medium consisting of basal salts, $2 \%$ sucrose and $0.5 \%$ yeast extract a 2.5 -fold, the mineral TKI medium without expensive complex components was further optimized because of cost-effectiveness.

\section{Influence of different carbon sources on spore formation of B. bassiana}

The highest concentrations and yields of TS and SCS were obtained in the TKI medium with $5 \%$ sugar beet molasses as a carbon source. It should be pointed out that the concentration of TS could be increased up to 11 -times in contrast to the cultivation with $5 \%$ sucrose in spite of the lower sucrose concentration of $2.5 \%$ in the molasses. The utilized sugar beet molasses consisted of $50 \%$ sucrose and only traces of other sugars like glucose, fructose and raffinose as well as different proteins and basal salts according to manufacturer specification
(Suedzucker AG, Mannheim, Germany). Furthermore, it could be shown that in addition to the present basal salts of the sugar beet molasses the TKI medium is necessary for optimal growth of $B$. bassiana. Sugar beet molasses is a residue of the agricultural industry and consequently, it is a low-cost source, which is a big advantage compared to other carbon sources. Therefore, the cost of $1 \mathrm{~L}$ TKI basal medium amended with $5 \%$ sugar beet molasses amounts to only $0.31 €$.

\section{Fermentation of $B$. bassiana ATP-02}

After the optimized cultivation of B. bassiana ATP-02 in shake flasks the process was scaled-up to a $2 \mathrm{~L}$ stirred tank reactor. Based on the cultivations in shake flasks $B$. bassiana ATP-02 was cultivated in the TKI mineral medium with $5 \%$ sugar beet molasses. In a preliminary test the fermentation was inoculated with a 5-days old shake flask culture of $B$. bassiana, which contained only BS. During the fermentation the fungus produced only mycelium (data not shown). Since the objective of cultivation was a high concentration of TS, further fermentations were inoculated with $5.0 \times 10^{4} \mathrm{AC} / \mathrm{mL}$. The achieved concentrations and yields of TS and SCS were comparable with the cultivation of B. bassiana ATP-02 in shake flasks and could be verified in 7 sequentially performed fermentation runs.

An unusual point during all fermentations is the sudden decrease of biomass dry weight in correlation with the low concentration of oxygen in the culture broth $72 \mathrm{~h}$ after inoculation. At this point it was observed that the finely dispersed mycelium lysed and the $\mathrm{pH}$ and the viscosity of the culture broth decreased. HPLC analysis indicated presence of oxalate. The reason for the rapid $\mathrm{pH}$ decrease in our fermentation is not clear, but it can be presumed that intracellular oxalate was suddenly released due to the lysis of mycelium. The following increase of $\mathrm{pH}$ suggests that oxalate was then metabolized by the growing spores. These presumptions are supported by other studies which also indicate that $B$. bassiana strains are able to produce, secrete and metabolize oxalate in vitro (Bidochka and Khachatourians 1993; Kirkland et al. 2005).

During the fermentation process the $\mathrm{pH}$ value was not regulated due to the fact that fluctuating $\mathrm{pH}$ values between 4.0 and 6.5 have no considerable impact on the growth of B. bassiana (Padmavathi et al. 2003; Thomas et al. 1987). The typical limitation of oxygen can be prevented by increase of the stirrer speed or agitation rate (Patel et al. 2011). But the primary objective of this fermentation process was not the production of finely dispersed mycelium but rather the mass-production of sprayable TS without any mycelium.

The recurring decrease of biomass dry weight in the spore formation phase cannot be explained in detail. It 
may be hypothesized that the mycelium is decreasing but the spore formation does not compensate the weight loss. It can be ruled out that spore biomass was lost during sample preparation as biomass was not filtered but centrifuged.

Furthermore, the achieved TS concentration and yield of the described fermentation process was higher than those obtained by other investigators in studies of liquid shake flask cultivations of epiphytic B. bassiana strains. For example, Thomas et al. (1987) reported a maximum concentration of $5.0 \times 10^{8} \mathrm{TS} / \mathrm{mL}$ corresponding to a yield of $1.00 \times 10^{10} \mathrm{TS} / \mathrm{g}$ glucose, Rombach (1989) described that $B$. bassiana produced TS in a maximum concentration of $0.17 \times 10^{9} \mathrm{TS} / \mathrm{mL}$ corresponding to a yield of $0.85 \times 10^{10} \mathrm{TS} / \mathrm{g}$ sucrose, Vega et al. (2003) obtained a maximum concentration of $1.24 \times 10^{9} \mathrm{BS} / \mathrm{mL}$ corresponding to a yield of $1.65 \times 10^{10} \mathrm{BS} / \mathrm{g}$ glucose and Pham et al. (2009) reported a maximum concentration of $0.85 \times 10^{9}$ $\mathrm{BS} / \mathrm{mL}$. The highest described concentration of BS was reported by Chong-Rodríguez et al. (2011), who obtained an inconsistent concentration of $6.38 \times 10^{9} \pm 3.63 \times 10^{9} \mathrm{BS} / \mathrm{ml}$ in a somewhat costly complex medium, which consisted of $5 \%$ sucrose, $2 \%$ corn steep liquor and basal salts. In comparison to other published data on cultivation of $B$. bassiana isolates in a solid-state or submerged cultivation it can be shown that the described fermentation process is very economical with regard to the achieved concentration and yield of TS. Furthermore, an obvious advantage of the fermentation process is that the cost of $10^{12}$ TS amounts to only $0.24 €$ with regard to the utilized culture medium. A further increase of the TS concentration can likely be realized by fed-batch fermentation.

\section{Insect virulence assay}

The mortality was $77 \pm 5 \%$ for $P$. xylostella larvae, which were fed with oilseed rape leaves treated with BS and SCS, and $90 \pm 5 \%$ for larvae fed with AC-treated leaves. These larvae mortalities are in accordance with those obtained by other investigators. Godonou et al. (2009) reported that $\mathrm{AC}$ of $B$. bassiana caused $P$. xylostella larvae mortality ranging from 20 to $94 \%$. BS which were sprayed on P. xylostella larvae showed a mortality ranging from 95 to 100\% (Fargues et al. 1983). In addition, ChongRodríguez et al. (2011) described that BS of B. bassiana maintained for six months at $4^{\circ} \mathrm{C}$ showed a mortality of more than $80 \%$ against third-instar P. xylostella larvae 8 days after application. Furthermore, Ortiz-Urquiza et al. 2010 observed that the composition of the culture medium affected the virulence of $\mathrm{AC}$ from $B$. bassiana because of an increased or decreased secretion of virulent proteins. But the influence of the culture media on the virulence of $B$. bassiana was not investigated in this work. Since no further mortality tests were conducted with pure BS and pure SCS, it can only be hypothesized that BS must have killed the larvae, because the spore mix consisted of $95 \%$ BS which are the preferred propagule of $B$. bassiana in the haemocoel of infected insects (Jackson et al. 2010; Shimizu et al. 1993; Sieglaff et al. 1997). Furthermore, BS are highly infective against a number of insect pests and have a lower $\mathrm{LD}_{50}$ when compared to AC or SCS (Hegedus et al. 1992). Finally, it was shown here that spores from a submerged cultivation are as virulent to $P$. xylostella larvae as AC.

\section{Penetration assay}

The simple penetration assay indicated that the spores from submerged fermentation show endophytic properties. This is in line with studies on AC that were applied to leaves and could to some extent colonize plants (Bing and Lewis 1991, 1992; Gurulingappa et al. 2010; Landa et al. 2013; Posada et al. 2007; Quesada-Moraga et al. 2006; Quesada-Moraga et al. 2009; Tefera and Vidal 2009; Wagner and Lewis 2000). Many questions about endophytism remain that are not within the scope of this fermentation study.

To the best of our knowledge, this is the first report of fermentation of an endophytic B. bassiana strain in a low-cost culture medium to very high yields of TS, which are able to penetrate oilseed rape leaves via a leaf application. This should further encourage the recent activities to exploit the biocontrol potential of endophytic entomopathogenic fungi. Besides, the evidence that the endophytic strain grows in simple cultivation conditions much like the classic biocontrol strains is further proof that in nature some microorganisms are facultative endophytes, which can optionally live inside plants and other habitats (Hardoim et al. 2008). The results also clearly suggest to further explore submerged cultivation for entomopathogenic fungi in general. Further studies are required to produce higher amounts of SCS of B. bassiana, which show a higher shelf life than thin-walled BS and may also persist longer when sprayed onto plant leaves.

\section{Abbreviations \\ AC: Aerial conidia; BS: Blastospores; SCS: Submerged conidiospores; \\ TS: Total spores; RQ: Respiratory quotient; CFU: Colony forming units.}

\section{Competing interest}

The authors declare that they have no competing interests.

\section{Authors' contributions}

$\mathrm{RL}$ designed and carried out the cultivations, fermentations and mortality tests, analyzed the data and wrote the manuscript. DJS carried out the molecular biology studies. AVP conceived of the study, and participated in its design and coordination and helped to draft the manuscript. All authors read and approved the final manuscript.

\section{Acknowledgements}

We would like to thank Prof. S. Vidal (Georg-August-University of Goettingen, Department of Crop Sciences/Agricultural Entomology) for providing the endophytic $B$. bassiana strain ATP-02 and the P. xylostella larvae. The research performed in this study was funded by the German Federal Ministry of Education and Research (FKZ 17 N1510). 
Received: 26 March 2014 Accepted: 4 May 2014

Published online: 29 May 2014

\section{References}

Akello J, Dubois T, Coyne D, Kyamanywa S (2008) Endophytic Beauveria bassiana in banana (Musa spp.) reduces banana weevil (Cosmopolites sordidus) fitness and damage. Crop Prot 27:1437-1441

Bidochka MJ, Khachatourians GG (1993) Oxalic acid hyperproduction in Beauveria bassiana mutants is related to a utilizable carbon source but not to virulence. J Invertebr Pathol 62:53-57

Bidochka MJ, Pfeifer TA, Khachatourians GG (1987) Development of the entomopathogenic fungus Beauveria bassiana in liquid cultures. Mycopathologia 99:77-83

Bing LA, Lewis LC (1991) Suppression of Ostrinia nubilalis (Hubner)(Lepidoptera: pyralidae) by endophytic Beauveria bassiana (Balsamo) Vuillemin. Environ Entomol 20:1207-1211

Bing LA, Lewis LC (1992) Endophytic Beauveria bassiana (Balsamo) Vuillemin in corn: the influence of the plant growth stage and Ostrinia nubilalis (Hübner). Biocontrol Sci Techn 1:29-47

Burges HD (1998) Formulation of microbial pesticides. Kluwer Academic Publishers, Dordrecht, The Netherlands

Chase AR, Osborne LS, Ferguson VM (1986) Selective isolation of the entomopathogenic fungi Beauveria bassiana and Metarhizium anisopliae from an artificial potting medium. Fla Entomol 69:285-292

Chong-Rodríguez MJ, Maldonado-Blanco MG, Hernández-Escareño JJ, Galán-Wong LJ, Sandoval-Coronado CF (2011) Study of Beauveria bassiana growth, blastospore yield, desiccation-tolerance, viability and toxic activity using different liquid media. Afr J Biotechnol 10:5736-5742

Fargues J, Reisinger O, Robert PH, Aubart C (1983) Biodegradation of entomopathogenic hyphomycetes: influence of clay coating on Beauveria bassiana blastospore survival in soil. J Invertebr Pathol 41:131-142

Feng MG, Poprawski TJ, Khachatourians GG (1994) Production, formulation and application of the entomopathogenic fungus Beauveria bassiana for insect control: current status. Biocontrol Sci Techn 4:3-34

Glare T, Caradus J, Gelernter W, Jackson T, Keyhani N, Köhl J, Marrone P, Morin L, Stewart A (2012) Have biopesticides come of age? Trends Biotechnol 30:250-258

Godonou I, James B, Atcha-Ahowé C, Vodouhè S, Kooyman C, Ahanchédé A, Korie S (2009) Potential of Beauveria bassiana and Metarhizium anisopliae isolates from Benin to control Plutella xylostella L. (Lepidoptera: plutellidae). Crop Prot 28:220-224

Gurulingappa P, Sword GA, Murdoch G, McGee PA (2010) Colonization of crop plants by fungal entomopathogens and their effects on two insect pests when in planta. Biol Control 55:34-41

Hall RA, Papierok B (1982) Fungi as biological control agents of arthropods of agricultural and medical importance. Parasitology 84:205-240

Hardoim PR, van Overbeek LS, van Elsas JD (2008) Properties of bacterial endophytes and their proposed role in plant growth. Trends Microbiol 16:463-471

Hegedus DD, Bidochka MJ, Khachatourians GG (1990) Beauveria bassiana submerged conidia production in a defined medium containing chitin, two hexosamines or glucose. Appl Microbiol Biotechnol 33:641-647

Hegedus DD, Bidochka MJ, Miranpuri GS, Khachatourians GG (1992) A comparison of the virulence, stability and cell-wall-surface characteristics of three spore types produced by the entomopathogenic fungus Beauveria bassiana. Appl Microbiol Biotechnol 36:785-789

Holder DJ, Kirkland BH, Lewis MW, Keyhani NO (2007) Surface characteristics of the entomopathogenic fungus Beauveria (Cordyceps) bassiana. Microbiology 153:3448-3457

Humphreys AM, Matewele P, Trinci APJ (1989) Effects of water activity on morphology, growth and blastospore production of Metarhizium anisopliae, Beauveria bassiana and Paecilomyces farinosus in batch and fed-batch culture. Mycol Res 92:257-264

Humphreys AM, Matewele P, Cunliffe B, Trinci APJ (1990) Comparison of sporulation of Paecilomyces farinosus and Beauveria bassiana in batch and fed-batch culture. Mycol Res 94:1046-1050

Jackson MA, Dunlap CA, Jaronski ST (2010) Ecological considerations in producing and formulating fungal entomopathogens for use in insect biocontrol. Biocontrol 55:129-145
Kassa A, Brownbridge M, Parker BL, Skinner M, Gouli S, Guo M, Lee F, Hata T (2008) Whey for mass production of Beauveria bassiana and Metarhizium anisopliae. Mycol Res 112:583-591

Khachatourians GG (1986) Production and use of biological pest control agents. Trends Biotechnol 4:120-124

Kirkland BH, Eisa A, Keyhani NO (2005) Oxalic acid as a fungal acaracidal virulence factor. J Med Entomol 42:346-351

Kučera M (1971) Toxins of the entomophagous fungus Beauveria bassiana: II effect of nitrogen sources on formation of the toxic protease in submerged culture. J Invertebr Pathol 17:211-215

Landa BB, Lopez-Diaz C, Jimenez-Fernandez D, Montes-Borrego M, Munoz-Ledesma FJ, Ortiz-Urquiza A, Quesada-Moraga E (2013) In-planta detection and monitorization of endophytic colonization by a Beauveria bassiana strain using a new-developed nested and quantitative PCR-based assay and confocal laser scanning microscopy. J Invertebr Pathol 114:128-138

Lane BS, Trinci APJ, Gillespie AT (1991) Endogenous reserves and survival of blastospores of Beauveria bassiana harvested from carbon- and nitrogen-limited batch cultures. Mycol Res 95:821-828

Leckie BM, Ownley BH, Pereira RM, Klingeman WE, Jones CJ, Gwinn KD (2008) Mycelia and spent fermentation broth of Beauveria bassiana incorporated into synthetic diets affect mortality, growth and development of larval Helicoverpa zea (Lepidoptera: noctuidae). Biocontrol Sci Techn 18:697-710

Núñez-Ramírez DM, Valencia-López JJ, Calderas F, Solís-Soto A, López-Miranda J, Medrano-Roldán H, Medina-Torres L (2012) Mixing analysis for a fermentation broth of the fungus Beauveria bassiana under different hydrodynamic conditions in a bioreactor. Chem Eng Technol 35:1954-1961

Odds FC (1991) Sabouraud('s) agar. J Med Vet Mycol 29:355-359

Ortiz-Urquiza A, Riveiro-Miranda L, Santiago-Álvarez C, Quesada-Moraga E (2010) Insect-toxic secreted proteins and virulence of the entomopathogenic fungus Beauveria bassiana. J Invertebr Pathol 105:270-278

Padmavathi J, Uma Devi K, Uma Maheswara Rao C (2003) The optimum and tolerance $\mathrm{pH}$ range is correlated to colonial morphology in isolates of the entomopathogenic fungus Beauveria bassiana - a potential biopesticide. World J Microb Biot 19:469-477

Patel AV, Jakobs-Schönwandt D, Rose T, Vorlop KD (2011) Fermentation and microencapsulation of the nematophagous fungus Hirsutella rhossiliensis in a novel type of hollow beads. Appl Microbiol Biotechnol 89:1751-1760

Pham TA, Kim JJ, Kim SG, Kim K (2009) Production of blastospore of entomopathogenic Beauveria bassiana in a submerged batch culture. Mycobiology 37:218-224

Posada F, Aime MC, Peterson SW, Rehner SA, Vega FE (2007) Inoculation of coffee plants with the fungal entomopathogen Beauveria bassiana (Ascomycota: hypocreales). Mycol Res 11:748-757

Quesada-Moraga E, Landa BB, Muñoz-Ledesma J, Jiménez-Diáz RM, Santiago-Álvarez C (2006) Endophytic colonisation of opium poppy, Papaver somniferum, by an entomopathogenic Beauveria bassiana strain. Mycopathologia 161:323-329

Quesada-Moraga E, Muñoz-Ledesma FJ, Santiago-Alvarez C (2009) Systemic protection of Papaver somniferum L. against Iraella luteipes (Hymenoptera: cynipidae) by an endophytic strain of Beauveria bassiana (Ascomycota: hypocreales). Environ Entomol 38:723-730

Rangel DEN, Dettenmaier SJ, Fernandes EKK, Roberts DW (2010) Susceptibility of Metarhizium spp. and other entomopathogenic fungi to dodine-based selective media. Biocontrol Sci Techn 20:375-389

Ravensberg WJ (2011) A roadmap to the successful development and commercialization of microbial pest control products for control of arthropods. Springer, Dordrecht, The Netherlands

Rombach MC (1989) Production of Beauveria bassiana [Deuteromycotina: hyphomycetes] sympoduloconidia in submerged culture. Entomophaga 34:45-52

Rombach MC, Aguda RM, Roberts DW (1988) Production of Beauveria bassiana [Deuteromycotina: hyphomycetes] in different liquid media and subsequent conidiation of dry mycelium. Entomophaga 33:315-324

Safavi SA, Shah FA, Pakdel AK, Rasoulian GR, Bandani AR, Butt TM (2007) Effect of nutrition on growth and virulence of the entomopathogenic fungus Beauveria bassiana. FEMS Microbiol Lett 270:116-123

Saha DC, Jackson MA, Johnsoncicalese JM (1988) A rapid staining method for detection of endophytic fungi in turf and forage grasses. Phytopathology 78:237-239 
Samsináková A (1966) Growth and sporulation of submersed cultures of the fungus Beauveria bassiana in various media. J Invertebr Pathol 8:395-400

Shimizu S, Tsuchitani Y, Matsumoto T (1993) Production of an extracellular protease by Beauveria bassiana in the haemolymph of the silkworm, Bombyx mori. Lett Appl Microbiol 16:291-294

Sieglaff DH, Pereira RM, Capinera JL (1997) Pathogenicity of Beauveria bassiana and Metarhizium flavoviride (Deuteromycotina) to Schistocerca americana (Orthoptera : acrididae). J Econ Entomol 90:1539-1545

Smith JE, Anderson JG, Deans SG, Berry DR (1981) Biochemistry of microcylce conidiation. In: Cole GT, Kendrick B (eds) Biology of conidial fungi,

vol 2. Academic Press, New York, NY, pp 329-353

Tefera T, Vidal S (2009) Effect of inoculation method and plant growth medium on endophytic colonization of sorghum by the entomopathogenic fungus Beauveria bassiana. Biocontrol 54:663-669

Thomas KC, Khachatourians GG, Ingledew WM (1987) Production and properties of Beauveria bassiana conidia cultivated in submerged culture. Can J Microbiol 33:12-20

Vega FE, Jackson MA, Mercadier G, Poprawski TJ (2003) The impact of nutrition on spore yields for various fungal entomopathogens in liquid culture. World J Microb Biot 19:363-368

Vogel HJ (1956) A conventional growth medium for Neurospora (Medium N). Microb Genet Bul 13:42-44

Wagner BL, Lewis LC (2000) Colonization of corn, Zea mays, by the entomopathogenic fungus Beauveria bassiana. Appl Environ Microbiol $66: 3468-3473$

doi:10.1186/s13568-014-0047-6

Cite this article as: Lohse et al.: Screening of liquid media and

fermentation of an endophytic Beauveria bassiana strain in a bioreactor. AMB Express 2014 4:47.

\section{Submit your manuscript to a SpringerOpen ${ }^{\circ}$ journal and benefit from:}

- Convenient online submission

- Rigorous peer review

- Immediate publication on acceptance

Open access: articles freely available online

- High visibility within the field

- Retaining the copyright to your article

Submit your next manuscript at $>$ springeropen.com 